INDIAN SECTION.

\title{
Leprosy in Women: Some Clinical Observations.
}

ISABEL KERR.

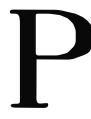

ROVIDED the chances are equal, the percentage of women infected by leprosy is similar to that of men.

In Africa, where women live under the same conditions as men, exposing themselves to the outside world in the same degree, it is found that the proportion of leprous men and women is equal. In China, in the neighbourhood of Canton, half to one-third of the people infected with leprosy are women. At Culion, Rodriguez gives 66 per cent. of men to 33 per cent. of women. Rogers and Muir give the percentage of leprous women in India as 28 . Here, at Dichpali, out of 400 inmates, 18 to 20 per cent. are women. This may be due partly to the fact that in a Mohammedan State, where the Zenana system is a mark of respectibility, women who can afford it prefer seclusion. Mostly women of a low caste are exposed to infection and these form a large percentage of our female patients here. These women of the lower castes work as coolies and for this reason would be likely to come in contact with infective leprosy. But even among women of this grade of society, infection is less prevalent than among men of the same grade. Women on the whole do not come into sufficiently close contact with other people or with one another to be likely to get infected. Because of their seclusion after the advent of puberty, fewer women than men are infected in later life.

The infections group themselves round the earlier years of life, and on examination the advance of the disease is found to depend on sex-development, child-bearing, and catamenial changes - always allowing for complicating factors such as chronic and acute complicating diseases, poor nutrition, etc., all of which will render the body tissues less resistant to leprosy. In a country like the Deccan where there is a fair amount of variation between night and day temperature, and the basal metabolic rate is presumably good, the progress of the disease is in many cases slow. We are, therefore, in a degree able to follow the advance of the disease and to detect the reasons thereof.

\section{Leprosy before Menstruation.}

Of the 16 small girls here under the age of puberty (not including cases of belated menses) the disease is in the 
maculo-anæsthetic stage in 14 , while in the remaining two it is cutaneous. Among the macular cases, a few are bacteriologically positive-M. lepræ being sometimes found in small numbers where there is thickening of the skin; but generally the patches are depigmented or appear as small, roundish areas which are scarcely visible and in which the lanugo hairs are unaffected. These children have been infected by their leprous relatives. Beyond their poor hygienic conditions, no complications can as yet be detected which is sufficient to break down their natural resistance further and cause a more virulent type of the disease. Before menstruation, the macular cases do well under hydnocarpate treatment. As many as 100 per cent. may be expected to recover. If complicated by syphilis, this treatment is difficult and prolonged while if menstruation is delayed, the patient would appear to have a better chance of improvement. Concomitant disease and menstrual periods tend to aggravate the leprosy and increase its virulence.

\section{Effects of Menstruation upon Leprosy.}

Among the direct causes of lepra reaction leading to aggravation of lesions, menstruation appears to play an important part. So far as the writer knows, the actual menstrual period has not been recorded as a cause of the first symptoms, or of the later exacerbations of, leprosy. This is possibly due to the fact that menstruation, in this country, at least, of ten synchronises with marriage, and the result is that symptoms of the disease are considered to be due to the beginnings of married life. In women, menstruation and maternity are the most serious causes of calcium deficiency in the tissues. Of the 100 women who are, or have recently been in this Home, five definitely trace the onset of leprosy in them as coincident with their early menses, while two of them particularise that symptoms appeared with their first period. Others assert that fresh lesions and aggravation of old lesions took place concomitant with their early menses. The writer has not actually witnessed the onset of the disease with the first menstrual period, but the aggravation of lesions during menstruation has of ten been observed. It is quite possible to watch the rhythmical advance of leprosy in many women during their menses.

\section{Menstrual Lepra Reaction.}

Lepra reaction is common in women whose menses is normal or increased in amount. All the symptoms of reaction may be present-temperature, fresh lesions, in- 
flammation of old lesions, while arthritis and neuritis may be slight or severe. Ephedrine or adrenalin may allay the nerve pain, but the cutaneous symptoms do not yield readily to potassium antimony tartrate. The latter pass off with or soon after the period. Preventive treatment only is effective. This menstrual lepra reaction may not be visible clinically. In many cases, it can only be detected by the sedimentation rate of the erythrocytes. This index should be checked as soon as the period commences. It may be raised 10 to 25 units higher than the patient's ordinary index. It is of importance to point out that the women in whom this periodic lepra reaction is found, have already a high S.I., whether the reaction is clinical or elicited by the S.I.

\section{Menstrual Irregularities in Leprosy.}

Menstruation among women suffering from leprosy is a subject of interest not only because it aggravates the disease, but also because of the variety of periodic disturbances found in connection with the disease. These variations would appear to be the result of two conditions :

1. A chronic leprous oöphoritis sufficient to cause amenorrhea and sterility (Glueck and Wodinsky).

2. A low alkali reserve concomitant with disturbance of the calcium blood level.

In women over 30 , the periods may disappear with the first signs of the disease, i.e., an early menopause. One would expect menstruation to be belated in skin cases which develop at an early age. But this is not always so. It is certain, however, that a normal or profuse menses if caused by a low calcium blood level, will militate against the improvement of the patient under treatment, while, if she remains untreated the progress of the disease will be accelerated. Under such conditions, we find that maculoanæsthetic leprosy tends to develop into skin leprosy.

\section{Relation of Syphilis to Menstrual Irregularities.}

Diseases which cause or are caused by calcium deficiency, readily affect the nervous system. An example of this is seen in tetany. In normal healthy persons, tetany is not found. If, however, the calcium level is disturbed by ulceration or dysenteric conditions, spasms due to stimulation of the myoneural junctions are manifest. Tetany does not occur in all cases of ulceration or dysentery. The exciting cause is an organism and the predisposing cause is lowered calcium level. Administration of calcium relieves the spasms. The exciting cause of leprosy is M. lepræ 
and one of the predisposing causes, if not the predisposing cause, may be a deficiency of calcium in the blood. Syphilis hastens the progress of leprosy from its earliest stages and predisposes to secondary nerve leprosy. It is extremely difficult in the writer's experience, to prevent skin leprosy from passing into the nerve type when syphilis is a complication.

Syphilis, more than any other complication in leprosy, seems to aggravate menstruation and cause this physiological process to become a morbid condition. The Kahn Test is positive in over 50 per cent. of the cases whose periods are apparently normal or increased, while it is positive in less than 25 per cent. of amenorrheic cases. Both menorrhagia and normal menses are lessened by calcium administration.

Amenorrhea, in the writer's opinion, is rarely due to syphilis directly. Signs of ovaritis-possibly leproticcan be elicited in a large number of women and girls whose menses is absent or repressed. Amenorrhea may also follow lepra fever and consequent calcium depression just as temporary amenorrhea follows febrile conditions such as scarlet and typhoid fever. This type of amenorrhea invariably yields to treatment.

In the 80 cases at present under observation, the mucous membrane of the vulva was bacteriologically positive in three cases, i.e., about 4 per cent. This was due to encroachment of skin lesions on the mucous surfaces. In no case were M. lepræ found in the vaginal discharges. This latter finding is a contrast to that of Babes, who reported $27 \mathrm{per}$ cent. of his cases bacteriologically positive. His findings have been corroborated by other investigators. Here, at Dichpali, no bacteriological examinations of the internal sex organs were made. The ovaries were palpated per rectum in these 80 cases and classification made according to the presence or absence of tenderness of these organs.

1. Normal menses with no ovarian tenderness. Of these, there were 19 cases, i.e., $24 \cdot 6$ per cent.

2. Normal menses or menorrhagia with ovarian tenderness. Of these, there were 21 cases, i.e., 27 per cent.

3. Amenorrhea with ovarian tenderness. Of these, there were 27 cases, i.e., 33.8 per cent.

4. Amenorrhea with no tenderness. Of these, there were 12 cases, i.e., $13 \cdot 8$ per cent.

In about half of these women, leprosy began after confinement-a factor which had to be taken into account concerning the cause of the pelvic pain. 


\section{Effects of Calcium Lactate and Sodium Bicarbonate on these Irregularities.}

In Class 1 , that is among the apparently normal cases, amenorrhea was induced in one case of active skin leprosy.

In Class 2, amenorrhea was induced in two cases, while in two others, the duration of the periods was shortened from four days to two days. In one case of severe menorrhagia whose periods recurred fortnightly, each time with a debilitating reaction, the periods were reduced to once a month and appear to have become normal. Lepra reaction ceased. On one occasion, Ext. Hydrastis was given to this patient.

Of the amenorrhea cases, partial or complete, there were 39 , i.e., nearly 47 per cent. Among those who complained of tenderness on palpation of the ovaries, two reported slight improvement of partial amenorrhea. Both were over 30 years of age and had had children.

Among those who had amenorrhea with no ovarian tenderness, i.e., amenorrhea apparently due to disturbed chemical balance of the blood, improvement was marked. Nine out of twelve (78 per cent.) improved. One case had had complete amenorrhea for two years ; two were cases of belated menses, while the others had been having diminished discharge once every few months.

\section{Treatment.}

All the female patients here receive creosoted ester hydnocarpate by injection twice a week. This is given intradermally and intramuscularly. In contrast to the male patients, the skin in the case of the women is soft and easily pierced, but their assimilation of the oil does not appear to be so rapid as in the case of the men. For this reason, only a small proportion take injections regularly. A year ago, on taking over charge of the female patients, the writer made inquiries regarding menstrual disorders. All disturbances were noted and for six months hydnocarpate treatment was persisted in, while attention was paid to complicating diseases in the usual way. Skin reactions were controlled by rest and potassium antimony tartrate. Six months later the menses were checked again. No radical changes could be detected and no cases of belated menses had begun to menstruate. Then calcium lactate and sod. bicarb. were added to the treatment-the calcium salt up to 30 grains per diem., while the sod. bicarb. was pushed so as to maintain the urine alkaline or neutral. Sod. bicarb. when given alone and in sufficient dosage to keep the urine 
alkaline, seems to cause neuritis. Injunctions were given to the patients to drink ample water with the salts. This led to a considerable increase in the amount of urine passed by the patients and demonstrated that the kidneys were hitherto insufficiently flushed.

At the same time, these salts were added to the treatment of 30 men. On the whole, the men responded more quickly to the alkali than the women. In them, the urine was more easily kept alkaline, and the S.I. improved more quickly. It would appear that the women have a lower alkali reserve than the men and, therefore, a lower calcium blood level. In both sexes, clinical lepra reaction was kept at a minimum and in several cases it disappeared, while in a few it reappeared if the alkali was suspended. No chemical estimation of blood calcium could be done here. This article, therefore, is confined to clinical details.

Menstrual disorders among leprous women can be an index of low calcium blood level. Previous to the use of calcium and sod. bicarb. as adjuvants in treatment, cutaneous and nerve lepra reactions were occurring periodically in 25 per cent. of the cases. Both have practically disappeared. It is worthy of note, however, that the cases who are really progressing are those who show no sign of menstrual lepra reaction whatsoever, but on the contrary, show a slowing of the sedimentation rate with their periods.

Administration of calcium and sod. bicarb. seem to compensate for relative deficiency of hormones (parathyroids and adrenals) caused by leprosy, or by its complications, or by physiological processes such as menstruation and maternity. If compensation is not made for this deficiency, the physical tone of the body is lowered and the result is aggravation of the leprosy.

In 90 per cent. of the women the urine keeps acid if alkali is not given. In the remainder it is alkaline. In a few cases of advanced skin leprosy, this alkalinity is constant. This may be due to renal dysfunction.

When menstrual lepra reactions cease the muscular tone in a woman improves. One would naturally expect that when she is relieved of a periodic lepra reaction which invalided her once, if not twice a month, her resistance to a chronic disease would be very much increased not by the treatment of this symptom of lowered vitality, viz., lepra reaction, but by the general building up of her body tissues.

These alkaline salts are not retained in the system and must be given repeatedly. 